\title{
AN INVESTIGATION OF THE CONTROLLING METHODS FOR THE SECONDARY LOSSES IN TURBINE BLADES
}

\author{
A. M .Alam El-Din, I. A .El-Sawaf, A. A. El-Abady and Y. K. Hassan \\ Mechanical Power Engineering Department, Faculty of Engineering, \\ Port Said University, Egypt
}

\begin{abstract}
Secondary flow remains a challenging task for both the researchers who pursue diligently their efforts to develop an improved understanding of the mechanisms of loss production and for the designers who endeavor to minimize the impact of losses on turbine performance by controlling the secondary flow and by reducing their interference with the main flow. As an extension to control secondary flows and losses reduction in turbine blades, this work introduces an experimental investigation which was carried out to establish the effect of endwall injected air on a turbine blade losses by different air jets location through flow channel between two consecutives blades and also with different inlet air flow speed at subsonic flow conditions through the blade cascade. Tests were conducted by using a linear cascade of turbine blades. The cascade was fixed on a wind tunnel and working as air flow supply. Measurements of wall static pressure on the pressure and suction sides of the blades, the total pressure at flow passage exit section and determination of flow loss for blade profiles are presented. The results showed readings changes due to the alteration of location and speed of endwall air jets. It is found that, the best results were recorded in the case of endwall air jets location at suction side of the tested blade with $\mathrm{M}=0.12$. Air jets successfully diverts the path of the passage vortex and decreases its effect on the suction side blade by creating higher static pressure on pressure side $(10.2 \%$ higher in blade pressure loading than on case without air injection application) and preventing boundary layer separation at suction side and also This modification has a significant effect to create a homogeneous pressure distribution through blade chordwise and hence reducing the possibilities of flow vortices existence then reducing the undesirable effects of secondary flow.

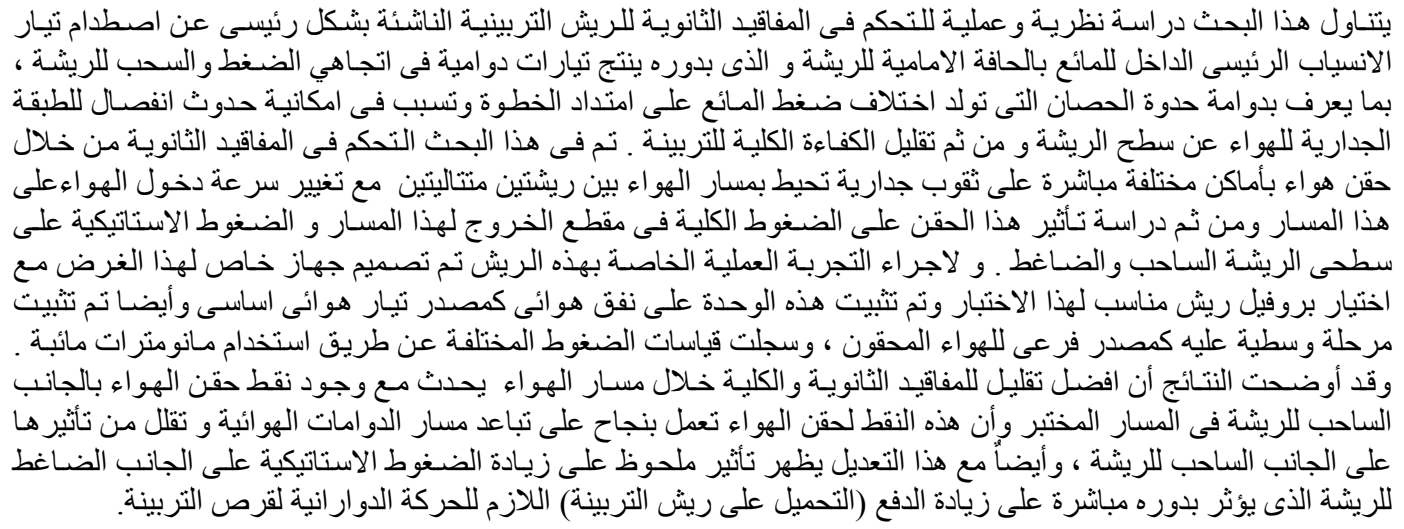

Keywords: Secondary losses, Turbine blades, Air injection, Pressure distribution, Boundary layer separation, Endwall jets, Passage Vortex and Blade loading.

\section{INTRODUCTION}

An important problem that arises in the design and the performance of axial flow turbines is the understanding, analysis, prediction and control of secondary flows. The designer of work extraction flow paths of such turbomachines - e.g. in a gas turbine - might define secondary flow as that which is not primary. Customarily, primary or uniform flow is an idealized two-dimensional form of the streamlines between the suction and pressure surfaces of a turbine blade passage. Flow deviations from the idealized form have come to be called "secondary", even though their presence may 
constitute whole regions of the turbine blade passage flow field. Secondary flows include endwall boundary layers, their separation, and other portions of the primary flow influenced by three-dimensional effects. During the last two decades, mastery of secondary flow phenomenon has become critical to modern turbine designs [1].

Gregory-Smith [2] describes the basic physics behind the generation of the passage vortex. When a sheared flow such as a boundary layer forced around a turn the slower moving fluid follows a tighter radius of curvature, leading to a tangential flow across the passage. Then, in order to preserve continuity, a vortical flow is formed. The above description only applies to the formation of the passage vortex which tends to dominate the flow field in the machine. When the boundary layer fluid approaches the blade leading edge, it is subjected to an adverse pressure gradient and starts to roll up to form a horse shoe vortex with two legs as shown in Fig. (1), one to pressure side (move away from the pressure surface and toward the suction surface of the adjacent blade to be the major component of the passage vortex) and the other to suction side (travels along the suction surface toward the trailing edge), it moves away from the endwall toward the midspan and down stream to the separation bubble [3].

Secondary flows have a number of undesirable effects as described by Gregory-Smith [2]:

1- The work output from a turbine stage depends mainly on the turning of the flow; secondary flow alters the flow angle in the tangential direction which changes the work output.

2- An extra loss generates a non uniform flow which is exist at exit of the blade row and reducing the efficiency of the blade row downstream.

3- Secondary flows can introduce unsteadiness into the flow which can cause mechanical problems.

4- The secondary flow provides non uniform heat transfer across the blade and endwall surface.

Secondary flow controlling methods according to most of previous studies are mainly classified to two categories [4] \& [5], the first category is dealing with structural measures in blade or endwall geometry and the second category is dealing with injection or suction of air directly to the flow passage. This study introduce an experimental investigation which was carried out to establish the effect of endwall injected air on a turbine blade losses by different air jets locations through flow channel between two consecutives blades and also with different inlet air flow velocity at subsonic flow conditions through blade cascade, by measuring the static pressure on both blade surfaces (pressure and suction sides) for blade pressure loading calculations and also measuring the total pressure at flow passage exit section for determination of profile losses, secondary losses and total losses.

\section{EXPERIMENTAL SET UP}

The experimental rig was designed and constructed to study the aerodynamic characteristics through a straight turbine cascade; it consists of the blade cascade, the air guide, the injected air flow system, the wind tunnel set and the measuring instruments.

The blade cascade is made up of six similar blades of chord $51.4 \mathrm{~mm}$ and the height is $60 \mathrm{~mm}$ [6]. The blades were placed equidistantly with a fixed pitch of $3.8 \mathrm{~cm}$ along the cascade height. The blades were bounded and fixed by two parallel flat fiber plates as shown in Photo (1) and Photo (2). The blades were made of aluminum and polished to give smooth surfaces. The blade wall pressure distributions were measured by ten taps made along the suction and pressure sides.

The air guide consists of two transparent plastic parallel plates expanded up and down the blades. Two side plates are shown in Fig. (2), Fig. (3) and Photo (3). These plates are used as an air guide at the enterance of cascade to obtain the uniform flow upstream of blade channels and the blades were placed in such away to allow an air inlet angle of $90^{\circ}$. A metal normal angle strips is bolted at the air guide inlet section to install and support the mounting panel by using 14 screws. And also to give the air guide more stiffness. Two wooden side plates $(21.5 \mathrm{X} 6 \mathrm{X}$ $4 \mathrm{~cm}$ ) were used with a curvature at the inlet side to avoid aerodynamic turbulence resulting from severe area step in air flow.

The injected air flow supply stage is used as an injected air supply to study the controlling of the secondary losses by application of air injection on air flow through the cascade as shown in Fig. (3) and Photo (4). This supply stage is installed at the wind tunnel output air section and then the blade cascade was installed on the injected air flow stage. This supply stage provide the blade cascade with 6 injected air sources by using 3 upper tubes and 3 lower tubes from the supply stage directly to the cascade and also transfers the main air flow from wind tunnel to blade cascade .

The subsonic wind tunnel is an open circuit rig powered by a 7.5 horse power induction motor $(2900$ r.p.m, and $50 \mathrm{~Hz}$ ) [7]. An air breather installed to allow air to be drawn in as required enabling one point in the system to be maintained at a constant pressure throughout the run. The air breather contains dust filters. The air in the system, therefore relatively dust free passes through a pipe section and flexible coupling section before entering the contraction, finally passing through three fine mesh wire gauze screens which reduce the turbulence level and also remove any swirling component in the flow. After a straight walled parallel pipe, the flow is accelerated by a contraction (2.35 area ratio) into the test section. The control valve installed, connected to the main 
parallel pipe through a contraction, provides a mean of varying the test section inlet air speed (within the range $30-45 \mathrm{~m} / \mathrm{s}$ ). This valve can be controlled automatically or manually. The general layout of the wind tunnel is shown in Fig. (3).

The stagnation pressure before the cascade blade P01 was measured by Pitot tube, placed before the cascade in the center of the guide flow channel. The Pitot tube is a copper tube with $2 \mathrm{~mm}$ inner diameter and $3 \mathrm{~mm}$ outer diameter fixed in the cascade arrangement, the Pitot tube is connected by a plastic tube to a $\mathrm{U}$ tube manometer uses a water as a fluid manometer.

The stagnation pressure readings after the cascade blade $\mathrm{P}_{02}$ was measured by a 3 hole Pitot tube arrangement as shown in Fig. (4), Fig. (5) and Photo (3). It consists of three circular steel tube with 1.0 $\mathrm{mm}$ inner diameter and $1.5 \mathrm{~mm}$ outer diameter, which is fitted through a bar of $7 \mathrm{~mm}$. inner diameter. These 3 tubes are fixed on a rotating base to assure the correct angle of the three tubes with the flow stream to obtain the exit stagnation pressure. The three tubes are connected by 3 plastic tubes and then connected to another $3 \mathrm{U}$ tube manometers with water as a manometer fluid), which give us indication about the flow direction and the value of outlet flow angle. In this experiment the outlet flow angle $\alpha 1$ was constant (15 degree).The pressure readings were measured using three-hole pressure probes. To control and adjust the position of the three-hole probe along the test section, a three-dimensional traverse mechanism was used at the exit section.

The static pressure of blade surface at both pressure side and suction side is the most significant parameter that can emphasize the experiment progress and results. The selected flow passage was located between two identical and adjacent solid blades at middle of blade cascade. those both selected blades have ten passages per each blade from the lower side of the cascade to middle of blade chord with $2.5 \mathrm{~mm}$ diameter (these 10 passages were distributed at blade mid chord section from the blade leading edge to the blade trialing edge, to cover the whole blade chord). These passages were drilled normally to the blade surface. Suction and pressure surface holes are facing each other in the same flow passage. Measuring static pressure is obtained by using ten copper tubes with a diameter of $2.5 \mathrm{~mm}$ and connected to plastic tubes to $U$ tube-water fluid manometers as shown in Fig. (3) and Photo (5)

A standard orifice plate is used to measure the injected air flow quantity as shown in Photo (6). This orifice is connected to 6 injected air supply tubes, 3 tubes upper source and 3 tubes lower source and the pressure drop across the orifice is measured by Utubes water manometers as shown in Fig. (3), Fig. (6) and Photo (4). This leads to injected flow quantity by equation (5), [8].
The experimental data for the total and static pressure readings before and after the blade cascade and within the blade chord were taken for 8 cases of injected air application to the flow channel. For every case the flow velocity is varied by adjusting the pressure reducing valve of the wind tunnel set there were 3 readings for different air flow velocities $(2,4$ and 6 valve positions) to cover the range of experiment between

\section{$0.1<\mathrm{M}<0.12$ and these 8 cases as follows:}

The base line $(\mathrm{N})$ for this experimental work is without any air injection and the flow is normal. Another 7 methods were achieved with applying 3 each injected air jets upper and lower blade cascade at the following locations Fig (7);

1- Upstream flow passage (N1)

2- Leading edge (N2)

3- Mid chord line (N3)

4- Trailing edge (N4)

5- Blade pressure side (N5)

6- Blade suction side (N6)

7- Mid flow passage line (N7)

\section{MEASUREMENT ACCURACY}

Measuring conditions, device sensitivity, types of flow etc. may affect the accuracy of readings and referred to the uncertainty analysis [9], [10] and [11], the following considerations are taken into account in the present work.

\section{A. Pitot-Tube Errors}

The locations of the Pitot-tube, which was previously calibrated, were adjusted so that its opening cross section is perpendicular to the measured flow condition [12] and [13]. The resulting error was found, it accounts to a maximum value of $( \pm 3 \%)$ for an inclination angle of $\left( \pm 5^{\circ}\right)$ of the flow direction, So in the present experiments, these limitations are considered.

\section{B. Transmitting System Errors}

These errors depend upon the system of tubes which were connecting the measuring stations and the reading board. These errors may be due to the resistance change of the tubes. To avoid such error, nylon tubes were used with little flow resistance [14] and also reading were taken after assurance of its constancy. Readings were repeated many times and the mean value of different readings was used in calculations.

\section{Manometer Errors [15].}

By using this method of calculation, the maximum relative error is $5 \%$, and the minimum relative error in measuring pressure drop is $0.5 \%$. 


\section{Orifice Plate Error.}

The pressure drop across the orifice is measured by U-tube water manometers. The orifice plate calibration leads to a maximum error of $\pm 3 \%$ in determining the injected air flow quantity.

\section{E. Other Parameters Errors.}

Other parameters recorded during the experimental runs and the respective measurement uncertainties values are summarized in Table (1).

Table 1, The precision limits for the measured parameters

\begin{tabular}{|c|c|}
\hline Parameter & Precision limit \\
\hline Barometric pressure & $\pm 0.1 \mathrm{~mm} \mathrm{Hg}$ \\
\hline Static pressure gauge & $\pm 5 \%$ \\
\hline Dynamic pressure gauge & $\pm 5 \%$ \\
\hline Inlet air temperature & $\pm 0.1{ }^{\circ} \mathrm{C}$ \\
\hline Blade exit angle & $\pm 1 \%^{\circ}$ \\
\hline Air Inlet velocity & $\pm 1 \% \mathrm{~m} / \mathrm{sec}$ \\
\hline
\end{tabular}

\section{GOVERNING CALCULATIONS}

\section{A. Determination of the Profile Loss Coefficient}

The loss profile coefficient $\tau_{p r}$ is due to annulus wall boundary layer and their interaction with the blade row and also due to the three dimensional flow phenomena in the turbine blade cascade and was determined by measuring the total pressure along the blade pitch and then was calculated using Deich equation (1), [16].

$$
\tau_{p r=\varepsilon^{(k-1) / k}} \cdot \frac{1-\left[1-\frac{\Delta P_{i}}{\Delta P_{o}}(1-\varepsilon)\right]^{(k-1) / k}}{\left(1-\varepsilon^{(k-1) / k}\right)\left[1-\frac{\Delta P_{i}}{\Delta P_{o}}(1-\varepsilon)\right]^{(k-1) / k}}
$$

\section{B. B. Determination of the Secondary and Total Losses}

Overall energy losses in cascades of turbomachinery are normally subdivided into profile losses and secondary losses [17] and [18]:

$$
\tau_{t}=\tau_{p r}+\tau_{s}
$$

The cascade passage averaged total loss coefficient $\left(\mathcal{\tau}_{t}\right.$ ) is obtained by integrating the average profile loss coefficient along the blade height [12]. The secondary loss coefficient $\left(\tau_{s}\right)$ was determined by subtracting the measured midspan averaged profile loss coefficient ( $\tau_{p r}$ ) from the passage averaged total loss coefficient $\left(\tau_{t}\right)$ as follows:

$$
\tau_{s}=\tau_{t}-\tau_{p r}
$$

By using Equation (1), (2) and (3) with the recorded experiment results, it leads to the losses changes with inlet air velocity and blade spacing as shown in Fig.

(8) and (9).

\section{C. Determination of pressure loading on the blade}

By integrating the static local pressure across the blade chord and height on pressure side, the local static pressure is measured at the location of ten taps at blade mid height to measure the average value of blade loading. The higher pressure loading on the blade is translated into an increase in the available work from a turbine rotor as measured by the blade Zweifel coefficient. The Zweifel coefficient (Equation 4) represents the component of the integrated blade $\mathrm{Cp}$ distribution contributing to the direction of rotation for a rotating stage [19].

$$
\mathrm{Z}=\int \text { full-chord }\left(\frac{\mathrm{P}_{\mathrm{t}, \text { in }}-\mathrm{P}_{s, \text { local }}}{\mathrm{P}_{\mathrm{t}, \text { in }}}\right) \frac{\hat{e_{n}} \cdot \hat{e_{t}}}{C_{X}} d s
$$

The static pressure $\mathrm{P}_{\mathrm{s}}$ used for the evaluation of the above loss terms is taken from sidewall pressure tapping. The assumption was made that the spanwise variation of the static pressure is negligible. This average value calculated from different measurements along the pitch at the center of the blade cascade and also at variable distances along blade height for different values of exit Mach number. The blade pressure loading is calculated by integrating the local static pressure on blade pressure side using Simpson numerical integration method [20].

\section{D. Determination of the injected air quantity}

\section{rate $Q_{\text {act }}$ by using standard orifice}

The injected air quantity rate $Q_{a c t}$ through standard orifice and through blade cascade directed to flow passage is calculated by using Equation (5), [8];

$$
Q_{a c t}=C_{D} \cdot \frac{A_{2}}{\sqrt{1-\left(\frac{A_{2}}{A_{1}}\right)^{2}}} \cdot \sqrt{2 g H\left(\frac{\rho_{W}-\rho_{\text {air }}}{\rho_{\text {air }}}\right)}
$$

\section{EXPERIMENTAL RESULTS AND DISCUSSION}

By calculating the area for local static pressure on blade pressure side as shown in Figures (10) to (17) for every air injection case, the blade loading can be obtained by using Simpson numerical integration method. The results could be represented in Fig (18) and Fig. (19) as follows: 
In comparison between the above cases it is noticed that, in the case of blades without injection, the suction surface pressure distribution is affected due to the presence of the passage vortex, which sweeps the flow up from the endwall surface and leads to increase the boundary layer thickness. While the pressure distribution on the suction side in the case of creating the injected air near the trailing edge, has a values less than that in the case of blade without injection which leads to decrease the boundary layer thickness and hence affected losses.

Also it is noticed that from Fig. (11) upstream injection case, the static pressure of pressure side slightly increased at the middle points through blade chord and the pressure values of suction side were almost kept the same without notable change. This leads to, the flow characteristics have no significant effect by air injection upstream flow passage.

In the case of air injection at the blade leading edge, the distribution of the static pressure along the blade surface is presented in Fig.(12), it is noticed that, there is the same flow separation pattern for the three cases, the separation points by increasing inlet air flow speed are the same points for the three different cases with a negative local static pressure at blade suction side at points $(4,5,6,7,8,9$ and 10). This separation is generated by increasing inlet air flow speed which indicates that the injected air flow at blade leading edge has a harmful effect on air flow boundary layer on blade suction side.

The minimum overall static pressure values at blade pressure side surface are recorded in Fig. (15) and also for the three different inlet air flow speeds with air injection at pressure side, that means the injected air flows produce an undesired turbulencewake regions which directly cause a decreasing in local static pressure on blade pressure side.

The biggest values of static pressure on blade pressure side are recorded in case of air injection at suction side of the test flow passage channel as shown in Fig. (16) where, the injected air canceled the boundary layer separation at wake area of suction side near the trailing edge.

\section{CONCLUSIONS}

The important conclusions drawn from this study are:

1. Endwall jets located towards the suction side of a turbine passage were effective in altering the path of the pressure-side leg of the corresponding blade horse shoe vortex and produce an increase in static local pressure on pressure side $(10.2 \%$ increasing in blade loading comparing to base line case) and hence save more work for turbine rotation.

2. Endwall jets located towards the pressure side of a turbine passage, blade loading deteriorated and lost $16 \%$ comparing to the base line case and that is happened as a result of dissipation of blade pressure side boundary layer by the injected air and gives the worse condition for blade loading.

3. The vortex was not significantly weakened, but its migration across the passage toward the suction surface was partially blocked for the case of air injection through the cascade passage, the static pressure increases at the pressure side and decreases at the suction side.

4. The air injection leads to improve the mixing and control flow separation which reduces the secondary flow effects.

5. With a certain fixed entered air flow speed, the total and static exit pressure readings have not any significant change in their values neither with the no injection case nor with injection cases.

6. The air injection at the trailing edge leads to maximize the secondary and total losses.

7. The minimum value for profile losses are found with in the middle height point of the blade in the flow passage exit section for all inlet air flow speed.

8. The minimum values for total, profile and secondary losses are found with $\mathrm{M}=0.11$ and with increasing or decreasing the speed the losses were changed.

\section{RECOMMENDATION FOR FUTURE WORK}

1. Flow visualization techniques [21] may be needed to help more for understanding the flow characteristics through turbine cascade.

2. Studies are needed to understand the effect of changing the injection point locations on suction and pressure sides and investigate its effect on flow characteristics and secondary losses.

3. Computational Flow Dynamics (CFD) in three dimensional analyses may give more understanding about the control of secondary flow through the turbine cascade.

4. Also using visualizations techniques may provide a great help in analyzing and comparing the results in such modification studies concerning the flow aerodynamic characteristics and secondary flow.

5. The effect of changing or controlling the mass flow of injected air is also needed to give a useful information affects on controlling the secondary losses.

\section{REFERENCES}

[1] Nicole V. A, Ralph J V, Karen A. F. and Ryan M. S. "Secondary Flow Measurements in a Turbine Passage with Endwall Flow Modification" ASME Turbo EXPO, 2000.

[2] Gregory-Smith, D.G., "Secondary Flows and Losses in Axial Flow Turbines", ASME Journal of Engineering for Gas Turbine and Power, Vol. 104, 1982. 
[3] Langston L. S. , Nice M. L. and Hooper R. M. " Three Dimensional Flow within a Turbine Cascade Passage " ASME Journal of Engineering for Power Vol. 99, 1977.

[4] Alexeeve R. N. and Boussova I. A. "Approximate Method to Determine the Aerodynamic Losses for Twisted Turbine Blade Cascade", Thermal Engineering Journal December 1974.

[5] L. S. Langston "Secondary Flow in Axial Turbines ",Dept. Of Mechanical Engineering, Journal U-3139 University of Connecticut, Storrs, USA, 2001.

[6] Deich M. E., G. A. Filippov, and L. A. Lazarev, "Atlas of Axial Turbine Blade Characteristics Part 1: Methods of Profiling and the Aerodynamic Characteristics of Cascades," Mashinastroenic, Moscow, 1965.

[7] Yassen, E.Y. "An Investigation of Greenhouse Effect on Flow Through Ducts"A Master Thesis, Suez Canal University, 2003.

[8] Dixon S. L."Fluid Mechanics- Thermodynamics of Turbomachinary" 2nd edition 1975.

[9] Abernethy,R. B, Benediet, R. P., and Dowdell, R. B, "Measurement Uncertainty", ASME., Journal of Fluids Eng., Vol. 107 pp 161-164, 1985.

[10] Kline, S. J., "The Purposes of Uncertainty Analysis "ASME., Journal of Fluids Eng., Vol. 107 pp 153-160, 1985.

[11] Moffat, R. J., "Describing the Uncertainties in Experimental Results" Experimental Thermal and Fluid Science, Vol. 1, No. 1, pp 3-17, 1988

[12] Sabry, T. I, Alam El-Din A. M and Gamal H. M "Observation about Secondary Flow Controlling Mechanisms", Engineering Research Bulletin Vol. 17 Part 1 Menoufiya University, 1994.

[13] Hesketh, A., Trittrat, H. and Aubry, P., "Modernization of Steam Turbines for Improved Performance", GEC Review, Vol. 11, No.2, 1996.

[14] Mcleish T. and Gilmour H. "Secondary Flow" Research Center, Durham University Journal, 2003.

[15] Lisal et al., "Profile Losses of an Annular Cascade in Unsteady Periodic Flow ", ASME p.92-GT-135,1992.

[16] Deich M. E. and Lajpat R. "An Investigation of the Flow in Turbine Cascades with Off-Design Inlet Angles. The Pulsation Characteristics of the Flow" Thermal Engineering 30(5), 1983.

[17] Sieverding, C. H. "Recent Progress in the Understanding of Basic Aspects of Secondary Flow in Turbine Blade Passages", ASME Vol 107, April 1985
[18] Moore A. and Adhye L. " Unplanned Three Dimensional Flow Effects in a Turbine", ASME, 1985.

[19] Jeffery P. B, Rolf S. and Richard B R. "Turbine Separation Control Using Pulsed Vortex Generator Jets", Transactions of the ASME Vol. 123, 2001.

[20] Matthews, John H. (2004). "Simpson's Rule for Numerical Integration". Numerical Analysis Numerical Methods Project. California State University, Fullerton. Retrieved 11 November 2008.

[21] R.A. Van den Braembusschea, J.F. Brouckaerta, G. Paniaguaa, L. Briottet

"Design and Optimization of a Multistage Turbine for Helium Cooled Reactor", Nuclear Engineering and Design Journal, 2008.

[22] Goldstein R. J. and Spores R. A. "Turbulent Transport on the Endwall in the Region Between Adjacent Turbine Blades " ASME, Journal of Heat Transfer Vol, 110, 1988.

\section{NOMENCLATURE}

$\begin{array}{ll}A_{1} & \text { Orifice inlet area, }\left(m^{2}\right) \\ A_{2} & \text { Orifice exit area, }\left(m^{2}\right) \\ C_{D} & \text { Coefficient of discharge, }(-) \\ \mathrm{Cp} & \text { Specific heats gas at const. pressure, } \\ & \text { (Joule/kg K) } \\ e^{\wedge} n & \text { Unit vector normal to blade surface, }(-) \\ e^{\wedge} t & \text { Unit vector in rotational direction, }(-) \\ \mathrm{g} & \text { Gravity acceleration, }\left(\mathrm{m} / \mathrm{s}^{2}\right) \\ \mathrm{H} & \text { Pressure head, }(\mathrm{m}) \\ \mathrm{k} & \text { Ratio of specific heats of gas, }(-) \\ \mathrm{M} & \text { Mach number, }(-) \\ \mathrm{N} & \text { Base line case }(\text { without air injection }),(-) \\ \mathrm{P} & \text { Pressure, }(\mathrm{Pa}) \\ \Delta \mathrm{P}_{\mathrm{O}} & \text { Pressure difference of }\left(\mathrm{P}_{01}-\mathrm{P}_{2}\right),(\mathrm{Pa}) \\ \Delta \mathrm{P}_{\mathrm{i}} & \text { Pressure difference of }\left(\mathrm{P}_{01}-\mathrm{P}_{02}\right),(\mathrm{Pa}) \\ Q_{a c t} & \text { Injected air discharge rate, }\left(\mathrm{m}^{3} / \mathrm{s}\right) \\ \mathrm{S} & \text { Blade spacing, }(-) \\ \mathrm{Z} & \text { Zweifel coefficient, }(-)\end{array}$

Greek

$\varepsilon \quad$ The ratio of $\mathrm{P}_{2} / \mathrm{P}_{01,(-)}$

$\rho \quad$ Density, $\left(\mathrm{kg} / \boldsymbol{m}^{3}\right)$

$\tau_{p r} \quad$ Profile loss coefficient, (-)

$\tau_{s} \quad$ Secondary loss coefficient, (-)

$\tau_{t} \quad$ Total loss coefficient, (-)

$\alpha_{1} \quad$ Exit flow angle 
A. Alam El-Din, I.El-Sawaf, A. El-Abady and Y. Hassan, "An Investigation of the Controlling ....."

\section{Subscripts:}

$\begin{array}{ll}\text { Ex or } 2 & \text { Cascade exit conditions } \\ \text { In or } 1 & \text { Cascade inlet conditions } \\ \text { Local } & \text { Local blade conditions } \\ \text { st } & \text { Static } \\ \mathrm{s} & \text { Secondary } \\ \mathrm{t} & \text { Total } \\ \mathrm{w} & \text { for Water } \\ \text { air } & \text { for Air } \\ \text { 1, to 7 } & \text { Injection case numbers }\end{array}$

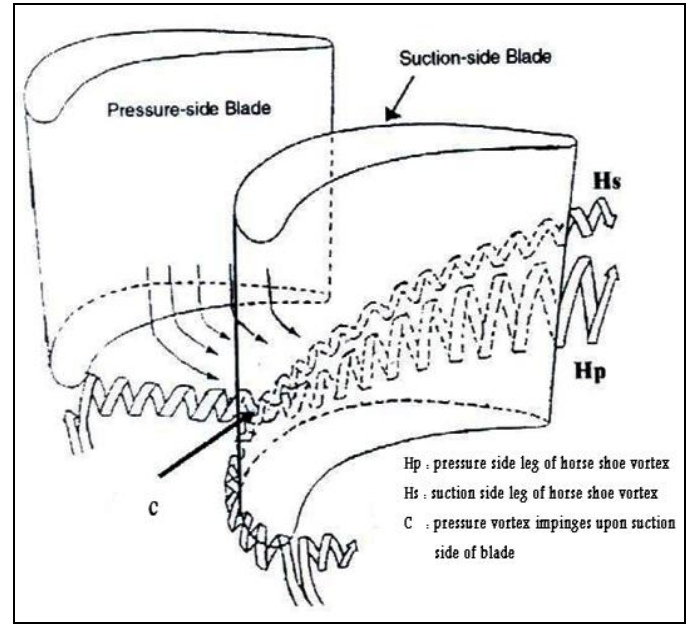

Fig. 1 Schematic of horseshoe vortex impinging upon suction-side blade [22]

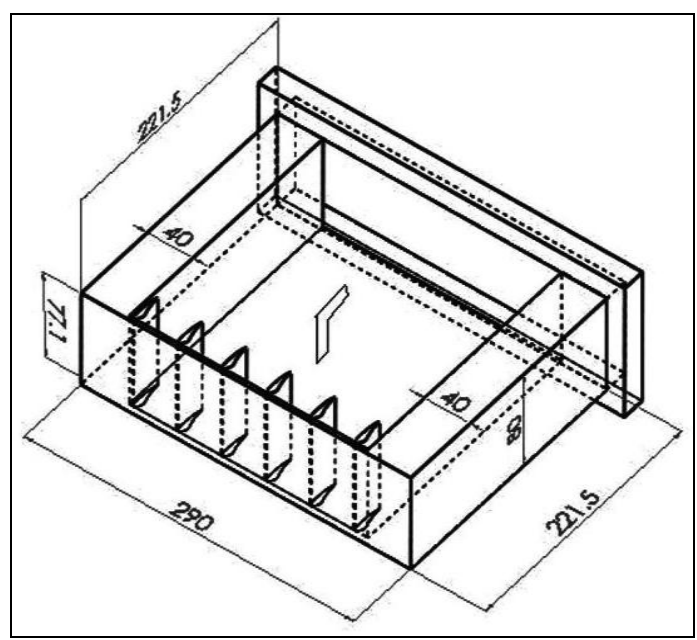

Fig. 2 Blade cascade dimensions in ( $\mathrm{mm})$

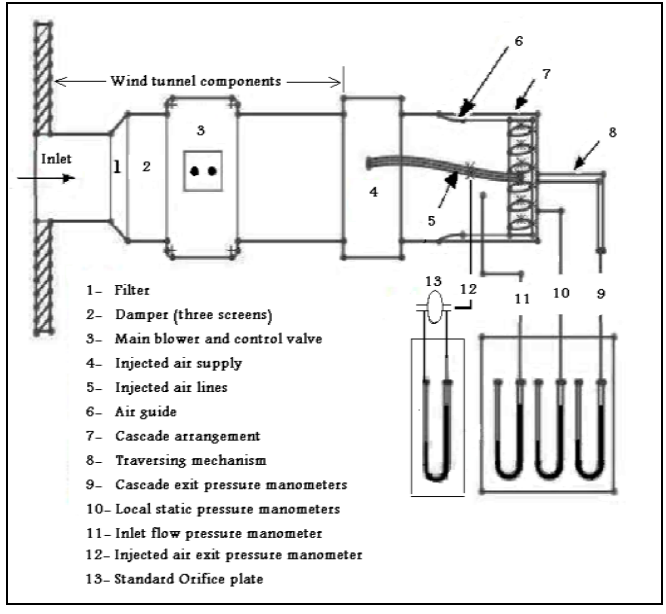

Fig. 3 Schematic of test rig general layout

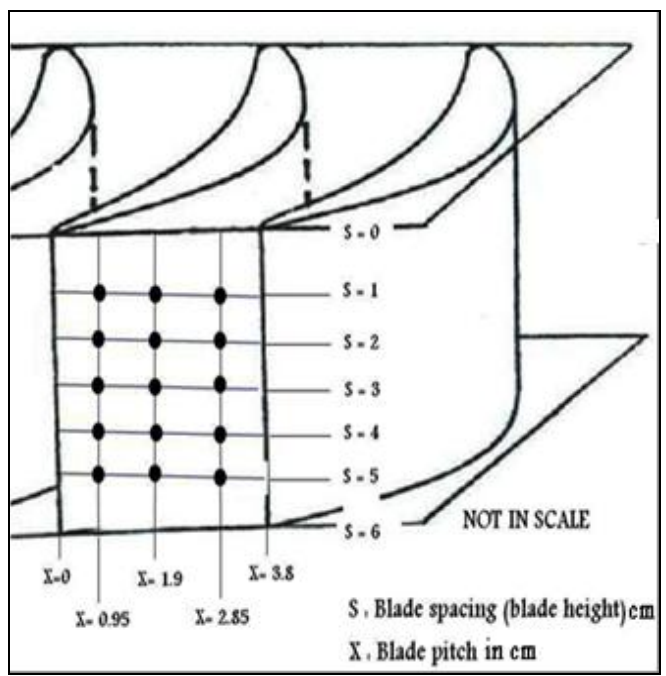

Fig. 4 Exit total pressure readings for different points at passage flow exit section

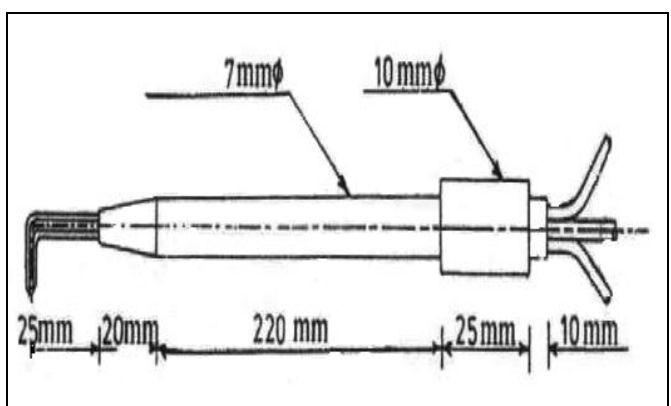

Fig. 5 3- Hole Pitot tube 
A. Alam El-Din, I.El-Sawaf, A. El-Abady and Y. Hassan, "An Investigation of the Controlling ....."

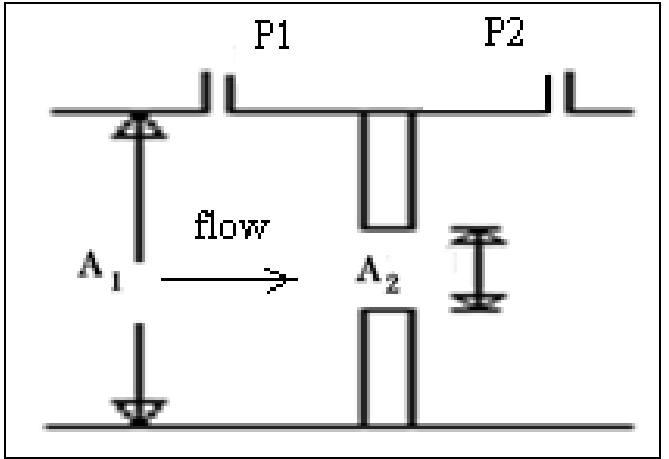

Fig. 6 Standard orifice plate

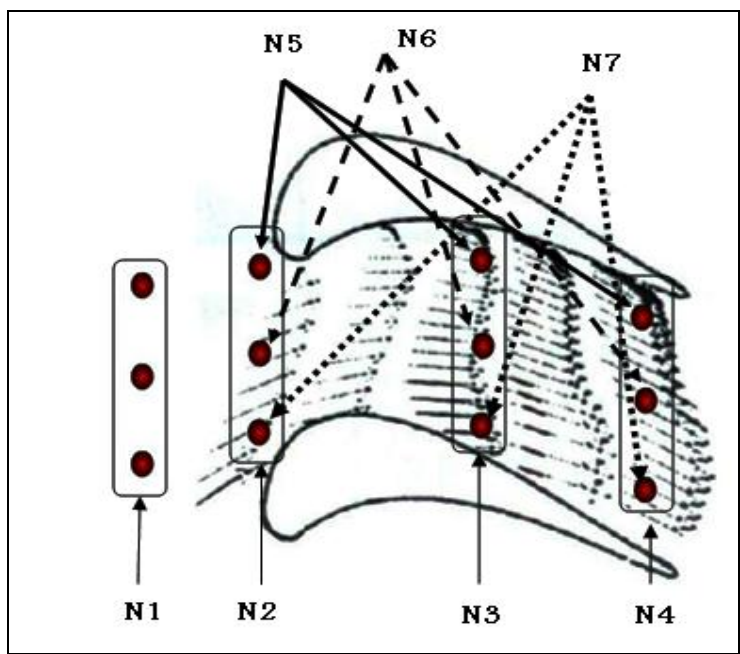

Fig. 7 The Injected points locations through flow passage

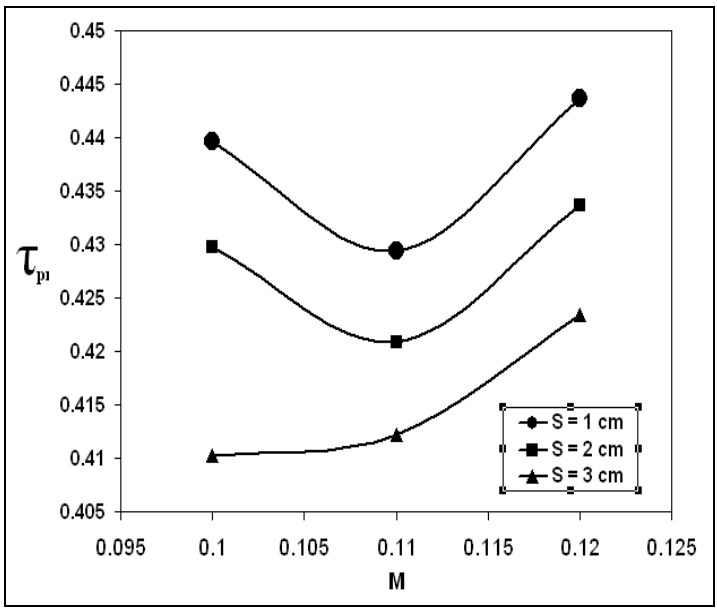

Fig. 8 Effect of Mach No. (M) on the profile loss coefficient

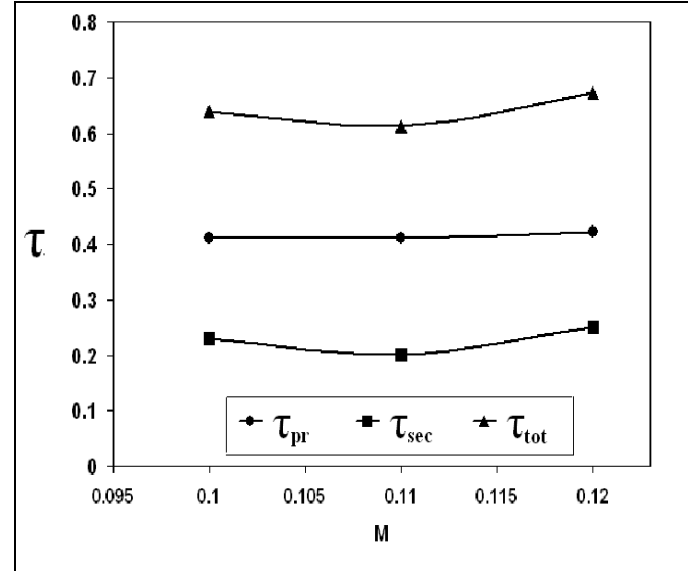

Fig. 9 Effect of the Mach No (M) on the loss coefficient

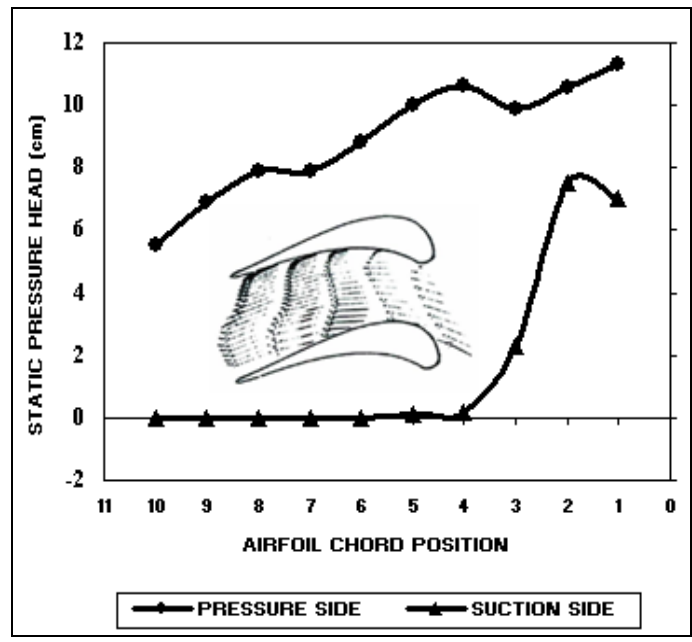

Fig. 10 Local static pressure on blade suction and pressure sides with base line, case $(\mathrm{N})$

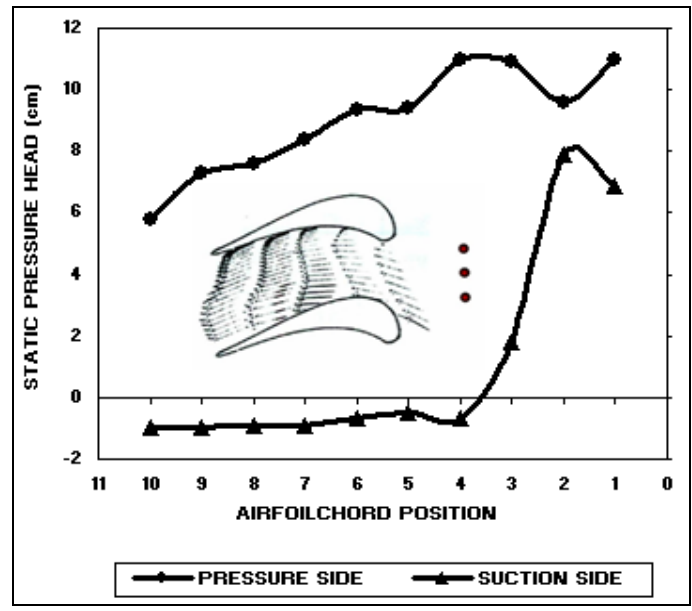

Fig. 11 Local static pressure on blade suction and pressure sides with air injection at flow upstream, case $(\mathrm{N} 1)$ 


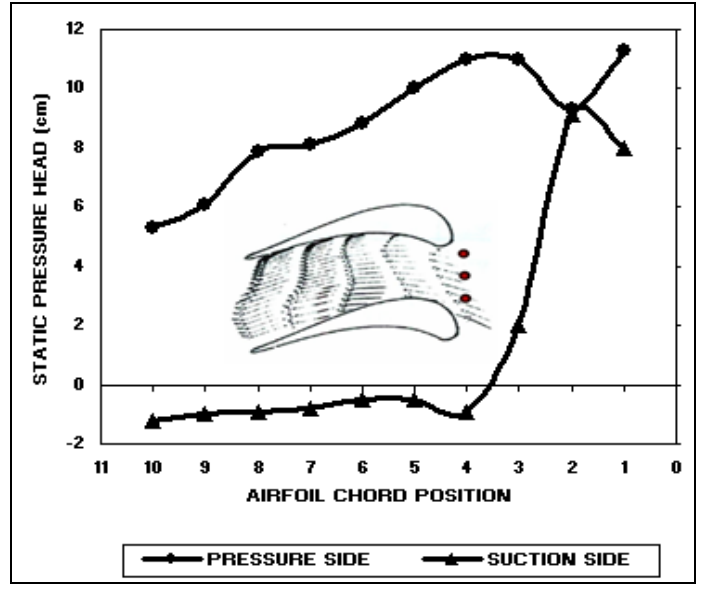

Fig. 12 Local static pressure on blade suction and pressure sides with air injection at leading edge, case (N2)

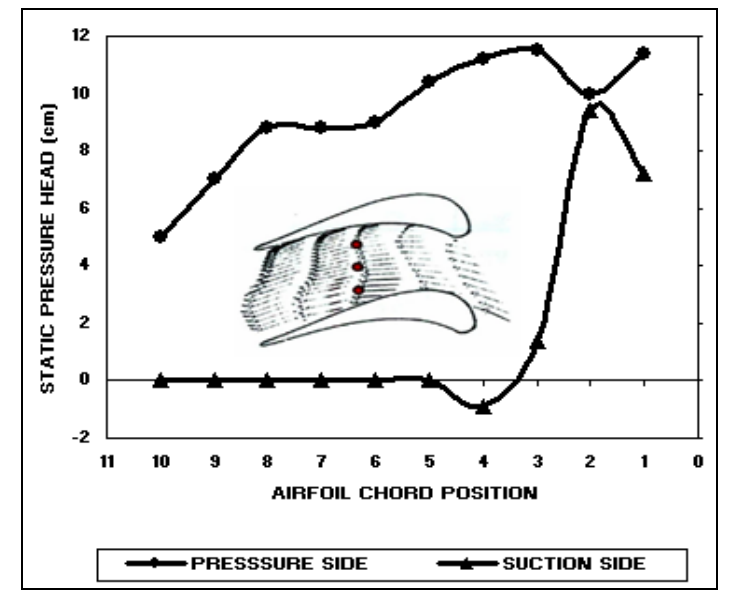

Fig. 13 Local static pressure on blade suction and pressure sides with air injection at mid chord line, case (N3)

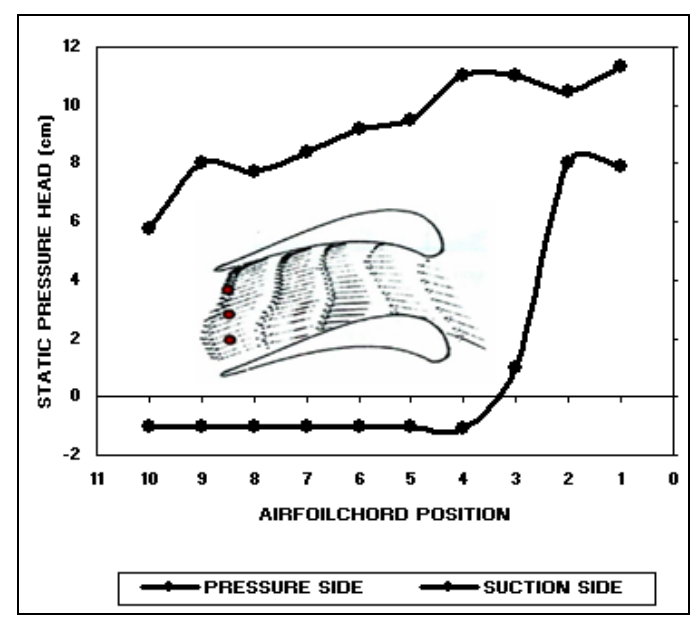

Fig. 14 Local static pressure on blade suction and pressure sides with air injection at T.E. section, case (N4)

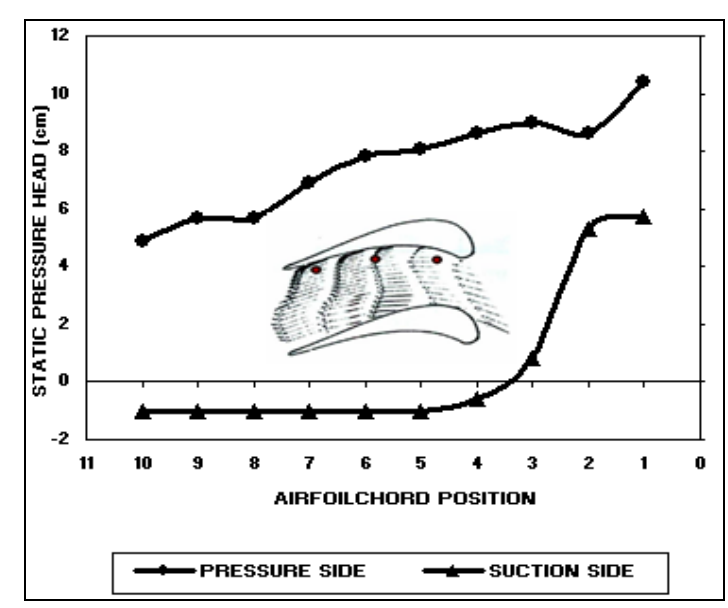

Fig. 15 Local static pressure on blade suction and pressure sides with air injection at pressure side, case (N5)

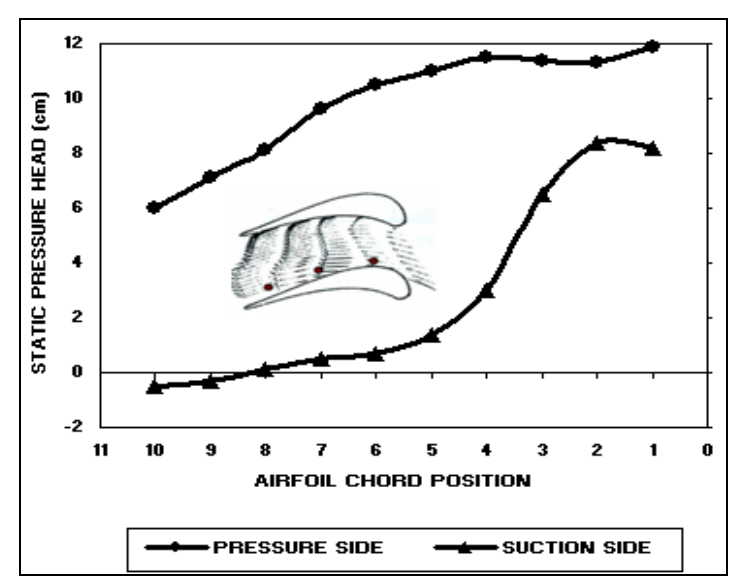

Fig. 16 Local static pressure on blade suction and pressure sides with air injection at suction side, case (N6)

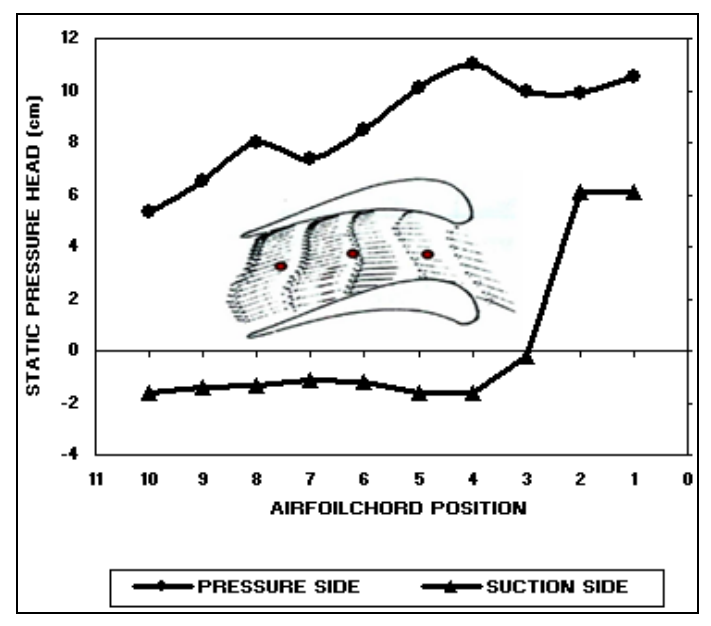

Fig. 17 Local static pressure on blade suction and pressure sides with air injection at mid line, case (N7) 


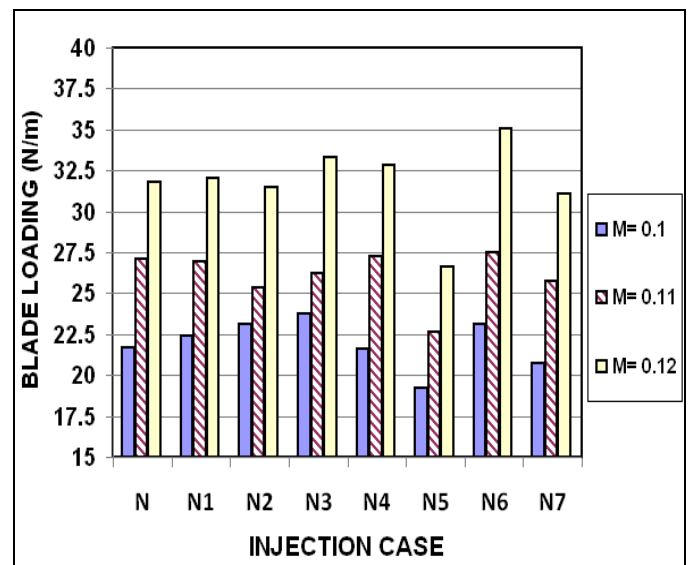

Fig. 18 Blade loading for different air injetion cases

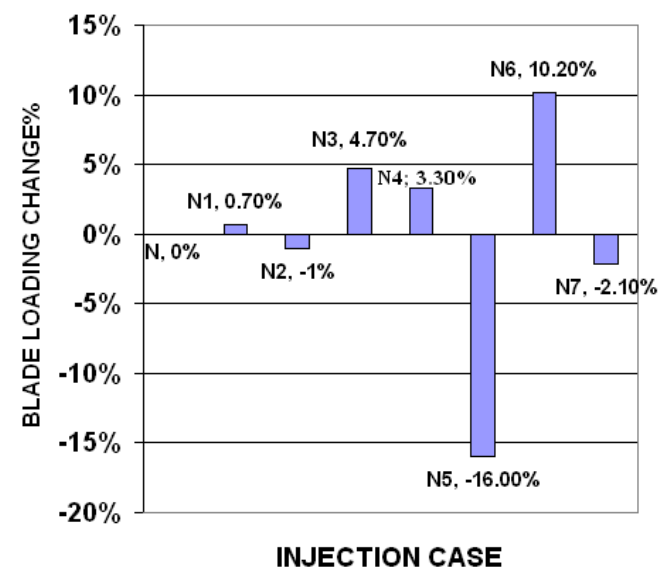

Fig. 19 Blade loading percentage change for different air injetion cases

Air injection cases;

1- Base line without air injection, case (N)

2- Upstream flow passage, case (N1)

3- Leading edge section, case (N2)

4- Mid chord line, case (N3)

5- Trailing edge section, case (N4)

6- Blade pressure side, case (N5)

7- Blade suction side, case (N6)

8- Mid flow passage line, case (N7)

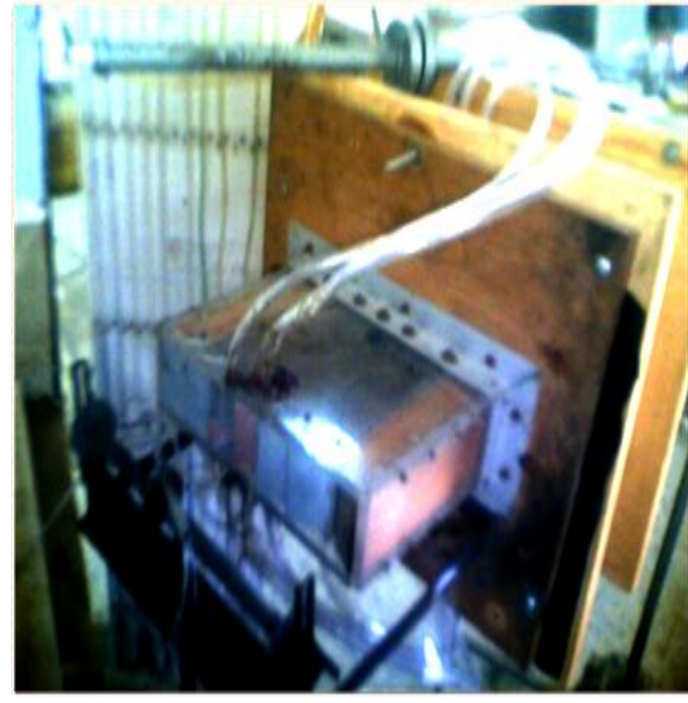

Photo (1) The blade cascade

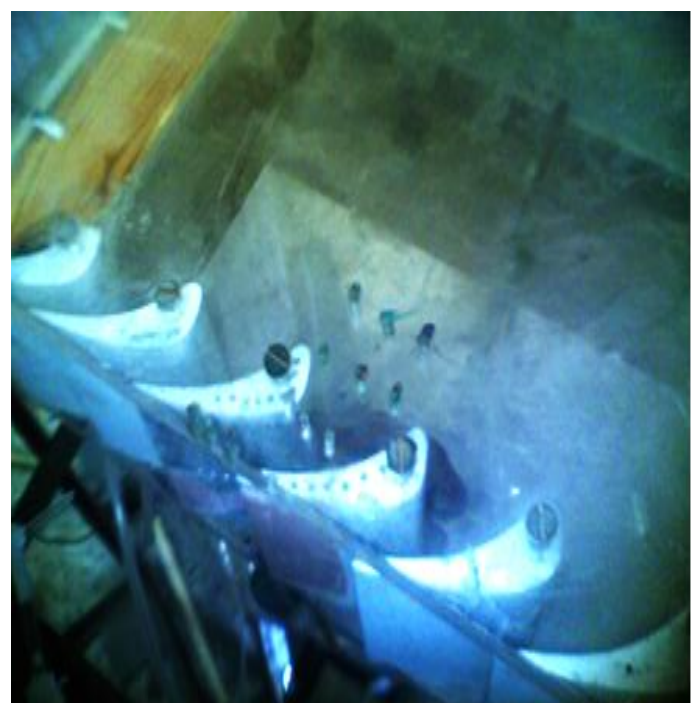

Photo (2) Six blades cascade 
A. Alam El-Din, I.El-Sawaf, A. El-Abady and Y. Hassan, "An Investigation of the Controlling ....."

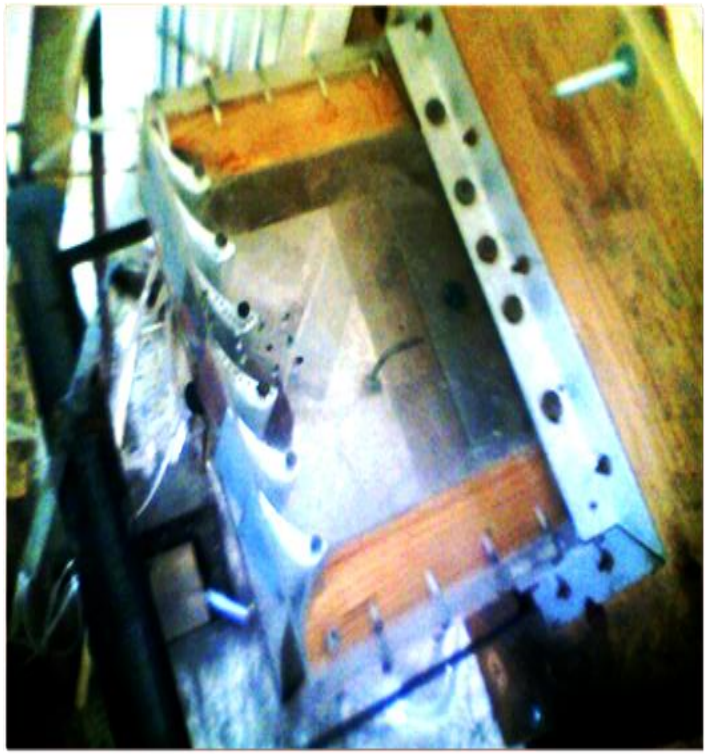

Photo (3) Air guide

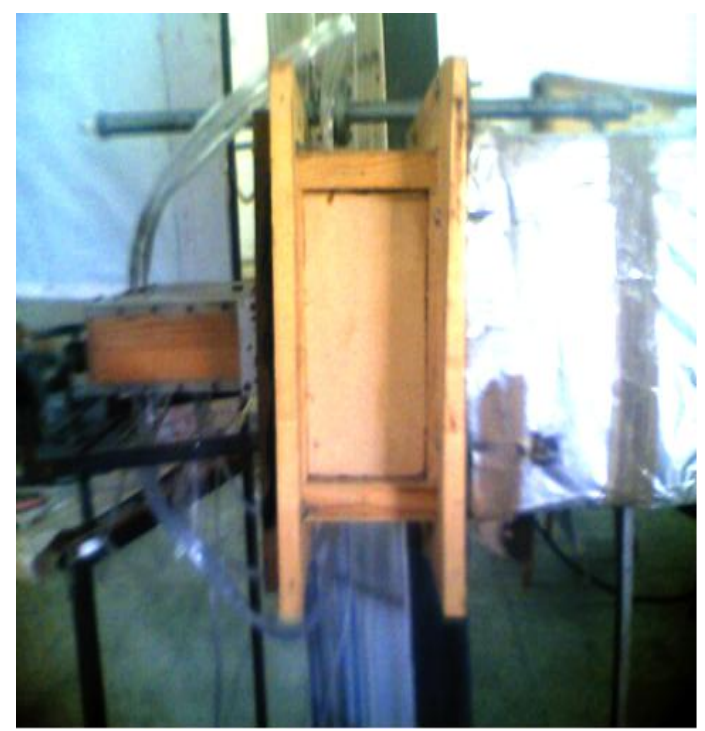

Photo (4) The injected air flow supply stage (connected between the blade cascade and the wind tunnel)

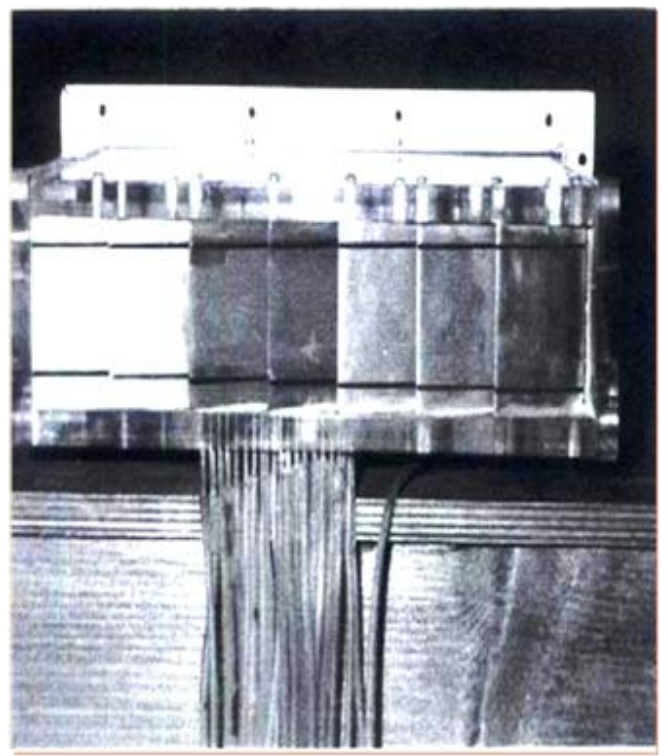

Photo (5) 20 plastic hoses of local static pressure measurements

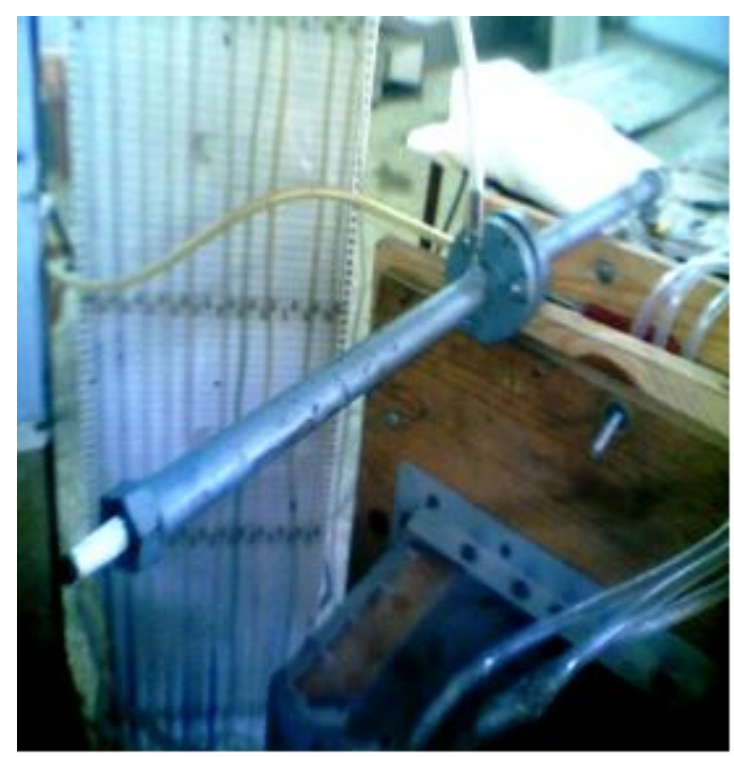

Photo (6) Orifice Plate 